\title{
Prediction method and practice of catalyst performance for SCR denitrification system Yongjin Liao ${ }^{1, a}$, Yuexi Yu ${ }^{1, c}$, Ye Wang ${ }^{1, d}$
}

\author{
${ }^{1}$ Electric Power Research Institute of Guangdong Power Grid Corporation ,Guangzhou510060, \\ China; \\ ${ }^{1}$ Electric Power Research Institute of Guangdong Power Grid Corporation ,Guangzhou510060, \\ China; \\ ${ }^{1}$ Electric Power Research Institute of Guangdong Power Grid Corporation ,Guangzhou510060, \\ China; \\ ${ }^{2}$ Bright Consult (Beijing) Co. Ltd.,Beijing 100028,China \\ alyj23455@163.com,,952374163@qq.com,,fanjunhui1026@163.com,,952374163@qq.com
}

Keywords: denitrification,catalyst, denitrification efficiency, performance prediction

\begin{abstract}
At present, Selective Catalytic Reduction (SCR) flue gas denitrification process has been widely used in coal power plants in China. Catalyst is the core of SCR denitrification system. Because of the influence of the fly ash, erosion and chemical poisoning, the catalyst activity can be reduced gradually, and the performance of the denitrification will be also reduced gradually. So it is significant to predict the safety and performance of the system. However, due to the limitation of laboratory test conditions, the test results can not completely reflect the actual situation of denitrification reactor, so this paper proposes the data of field performance tests of denitrification system to be modified, namely while laboratory test data of the catalyst used to control the degressive rate of the catalyst activity, the field test data of the denitrification system used to control the actual denitrification performance of the reactor. Meanwhile, this paper introduces the practice of the catalyst performance prediction fora 1000MW unit, which would provide a scientific basis for the management of SCR flue gas denitrification system.
\end{abstract}

\section{Introduction}

Nitrogen oxide (NOx),a major air pollutant,has serious effect on the earth's ecological environment and living being safety,and the coal-fired power stations has become the priority of the NOx emissions[1]. At present,Selective Catalytic Reduction (SCR), as a a main technical method for reducing the NOx emissions from coal-fired flue gas, has many advantages such as well selectivity, strong stability and high denitrification efficiency,which is widely used in coal-fired power plant.However, for the flue gas denitrification device,many scholars' research found that the catalytic activity of SCR was significantly decreased with the increase of the operating time,and similarly the denitrification performance decreased with the running time[2-6].So why?Probably the main reason is that the catalyst is affected by the fly ash, erosion and chemical poisoning[7].Therefore, the catalyst needs to be added periodically or replaced regularly to ensure the normal and efficient operation of the denitrification system and meet the requirements of the state on the nitrogen oxide emission in coal-fired power plants.So it is very significant for the performance evaluation and life prediction of the denitrification catalyst in coal-fired power plants, as well as the comprehensive understanding for the operating conditions of the catalyst and making the plan for catalyst management in coal-fired power plants.

The general approach to formulate a reasonable increase or replacement of the catalyst is to sample and make the unit sample from each layer of the SCR reactor,then test the denitrification efficiency and the activity $\mathrm{K}$ on the flue gas device in the laboratory [8-9], which to manage catalyst lifetime .However,because of the limitations of the laboratory test conditions, the test results could not reflect completely the actual situation of the denitrification reactor , which leads to the large error of the prediction for the catalyst performance.Consequently,this paper proposes the data of field 
performance tests on the denitrification system ,which to be modified. Namely, while laboratory test data of the catalyst used to control the degressive rate of the catalyst activity, the field test data of the denitrification system used to control the actual denitrification performance of the reactor. Meanwhile, this paper introduces the practice of the catalyst performance prediction for a $1000 \mathrm{MW}$ unit.

\section{A prediction method for the catalyst performance and its limitation}

\subsection{A prediction method for the catalyst performance.}

The catalyst ,as the core of SCR denitrification system, is the most principal factor affecting the overall denitrification performance of the system. The catalyst performance was characterized by the activity coefficient $\mathrm{K}$, which was obtained by measuring the denitrification rate of the catalyst samples under the test condition in the lab.

$$
\begin{aligned}
& K=-A V \times \ln (1-\eta) \\
& A V=\frac{Q_{F}}{V_{s y} \times A_{s y}}
\end{aligned}
$$

Among them,K as the catalyst activity,m/h; ${ }^{\eta}$ as the denitrification efficiency,\%;AV as catalyst area velocity,m/h;QF as test on gas flow,m3/h;Vsy as the volume of catalyst sample,m3;Asy as the surface area of catalyst sample,m $2 / \mathrm{m} 3$;

At present,there are mainly two kinds of measurement device for catalyst activity in industry that pilot experimental device and small scale device, of which the difference is mainly reflected in a selection of sample size and setting test conditions. Taking the detection of honeycomb catalyst as an example,the pilot experimental device directly selects the catalyst unit as the sample,of which the size of the actual length is $150 \mathrm{~mm} * 150 \mathrm{~mm}$.Therefore, it can be realized by using the actual parameters of the flue gas that including Including the area of speed, temperature, flue gas composition, ammonia ratio and its like as the test condition, which would be obtained that the absolute value of the rate and the activity of the catalyst in theory.However,the small scale device,cutting the catalyst unit into test blocks as the sample,which the length is about $200-400 \mathrm{~mm}$,the about $50 \mathrm{~mm} * 50 \mathrm{~mm}$ of cross section and at least including 4 holes in themselves, is a device for measuring denitrification performance. As the sample size is limited,the setting area speed will be higher than the actual value of the denitration device design.So,the catalyst denitration rate and activity $\mathrm{K}$ that obtained can become the relative values that based on the same test conditions, which can evaluate the relative levels of the catalyst activity in different samples.As the small scale device has the advantage of high testing precision ,VGB[10] in Germany has given the test deviation data of the two kinds of devices in catalyst testing standard.In addition, the average value of activity in the pilot experimental device is $39.2 \mathrm{~m} / \mathrm{h}$ and the standard deviation is $3.7 \mathrm{~m} / \mathrm{h}$, while in the small scale device that the average activity is $41.2 \mathrm{~m} / \mathrm{h}$, and the standard deviation test is $2.4 \mathrm{~m} / \mathrm{h}$.

The catalyst's potential $\mathrm{P}$,represents the denitrification capacity for the denitrification reactor,is the result that the obtained catalyst activity multiplied by the surface area of the catalyst. There is one of the most significant work for catalyst management that grasp the potential of the reactor by testing the catalyst activity and determine whether the catalyst meets the requirements of environmental protection.Fig. 1 as the example of tracking on the catalyst performance for a fossil fired power plant.

$$
P=\sum_{1}^{n} K_{n} * F_{n}
$$

Among them,P as the catalyst's potential, $\mathrm{m}^{3} / \mathrm{h} ; \mathrm{n}$ as catalyst layer;Kn as catalytic activity of the $\mathrm{n}$ layer; Fn as catalyst surface area of the $n$ layer, $\mathrm{m}^{2}$. 


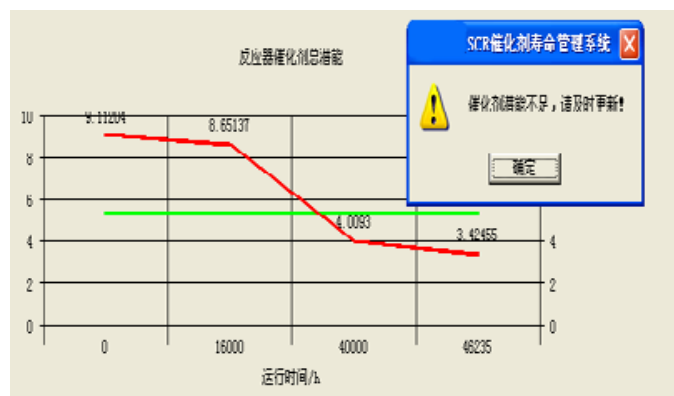

Fig.1 Tracking of the catalytic potential of denitrification reactor

\subsection{Limitations of forecasting methods.}

As the mentioned above, the core of catalyst performance prediction is the catalyst activity testing, but the absolute value of the catalyst activity could not be obtained from the small scale device.Although may be got from the pilot experimental device,still could not fully reflect the denitrification reactor performance, which the reason is:

(1) The site situation on the dust and wear of catalyst could not reflected.

The test unit should be required that in the surface cleaning, no plug and complete situation.However, there will be more or less dust, wear and so on for the catalyst in site situation, which lead to the deviation of the actual activity and the test activity.Besides,for the different units of denitrification reactor ,there will be with a large deviation and very difficult to be quantitatively evaluated in the case of dust,which may lead to be difficult to be accurately modified.

(2) An uneven distribution in flow field could not reflected.

Laboratory tests are only aimed at a single sample, which can not simulate the situation of flow field.At present,however,the flow field of a large number of denitrification reactors in China is not satisfactory, and the relative standard deviation of flue gas flow rate over $20 \%$ is common,In other words, there is no match between the test flow velocity in the laboratory and the actual situation so that the active data in the laboratory can not reflect the actual situation.

(3) The situation of the NH3/NO mole ratio with an uneven distribution in the field could not reflected.

Simultaneously,laboratory tests are only aimed at a single sample,which could control accurately the NH3/NO ratio of the test.But due to the uneven distribution in flow field and the uneven ammonia injection on site,or even by optimizing and adjusting the denitrification and ammonia injection system ,the NH3/NO mole ratio exceeds commonly the range from $-5 \%$ to $5 \%$, which can also lead to the deviation of laboratory data.

\section{Improvement and practice of the catalyst performance prediction method}

Due to the limitation of the catalyst performance prediction in the laboratory , the method adopted that performance testing of the denitrification system on the site should be modified.The reason is that:for a stable operation of the denitrification device, the flow field, ash, ammonia, and other conditions are basically stable, and through the measurement of the denitrification rate in the field ,which can calculate the actual activity and potential of the reactor.Then by comparing and correcting the activity data from laboratory, which can not only obtain the absolute value of catalyst activity in small scale device, but also solve the problem of the limitations to not reflect the flow field, dust, ammonia and other practical conditions in pilot experimental device.In other words,laboratory test data of the catalyst will be used to receive the catalyst activity of the reduction velocity, while the field test data of the denitrification system used to control the actual denitrification performance of the reactor.The following introduction-the practice of the catalyst performance prediction fora 1000MW unit.

The unit capacity ,with 2 layers of plate catalyst and 1 layer of honeycomb catalyst that has been running about 26000 hours, is $1000 \mathrm{MW}$, which to reach $80 \%$ for the actual denitrification rate to meet the environmental requirements. In order to know weather the Denitrification efficiency meets the requirements of environmental protection and when the catalyst is needed to update, the performance 
test on site and the catalyst activity test in laboratory are carried out.Different cellular and plate catalyst samples with the same test conditions to test the catalyst activity in the small scale device.According to the activity test results, the data of catalyst the layer surface area and catalyst running time,which can be calculated weighted average of catalyst activity of idle speed,then based on field test data to compute the running time that the denitrification system meet the environmental requirements.Tab. 2 as the result of calculation,the average decline rate of the catalyst activity was $10.01 \% / 10000 h$,and the actual denitrification rate was $83 \%$,so the denitrification rate will fall to $80 \%$ after the unit runs 9167 hours.

Table 1 Catalyst activity test results

\begin{tabular}{|c|c|c|c|}
\hline Catalyst type & Catalyst position & Catalyst activity（m/h) & Relative activity \\
\hline Honeycomb & New catalyst & 47.7 & 1 \\
\hline Plate & New catalyst & 48.3 & 1 \\
\hline Honeycomb & The down of $\mathrm{A}$ & 35.9 & 0.75 \\
\hline Honeycomb & The down of B & 32.5 & 0.68 \\
\hline Plate & The up of A & 33 & 0.68 \\
\hline Plate & The up of B & 34 & 0.70 \\
\hline Plate & The middle of $\mathrm{A}$ & 38.8 & 0.80 \\
\hline Plate & The middle of B & 39.7 & 0.82 \\
\hline \multicolumn{4}{|c|}{ Table 2 Prediction of denitrification performance for the unit } \\
\hline $\begin{array}{l}\text { Average } \\
\text { denitrification } \\
\text { rate }(\%)\end{array}$ & $\begin{array}{l}\text { The requirement for } \\
\text { denitrification rate in } \\
\text { unit (\%) }\end{array}$ & $\begin{array}{l}\text { The average inerting } \\
\text { speed of catalyst activity } \\
\text { in unit }(\% / 10000 \mathrm{~h})\end{array}$ & $\begin{array}{c}\text { The hours of } \\
\text { operation with } \\
\text { denitrification rate } \\
\text { fell to } 80 \%\end{array}$ \\
\hline 83 & 80 & 10.01 & 9167 \\
\hline
\end{tabular}

\section{Summary}

1) The actual situation of the products that the flow field, ash, ammonia injection and its like for the denitrification reactor would be not simulated by both pilot experimental device and small scale device.Therefore, the SCR catalyst activity can not reflect the actual denitrification performance of the reactor.

2) Due to the limitation of the catalyst performance prediction in the laboratory , the method adopted that performance testing of the denitrification system on the site should be modified.Through the measurement of the denitrification rate in the field ,which can calculate the actual activity and potential of the reactor.That is to say,laboratory test data of the catalyst will be used to receive the catalyst activity of the reduction velocity, while the field test data of the denitrification system used to control the actual denitrification performance of the reactor.

3) The performance test and prediction for the de-NOx equipment of a 1000MW unit were carried out in the field and laboratory, of which the result that the denitrification rate would fall to $80 \%$ after the unit running 9167 hours.

\section{References}

[1]. CHEN Jinsheng. The Selective catalytic reduction method for flue gas denitrification in coal fired power plant.[M].Beijing:Electric power press in China,2008.

[2]. ZHANG X L, HUANG Z G, LIU Z Y. Effect of KCl on selective catalytic reduction of NO with NH3 over a V2O5/AC catalyst [J].Catalysis Communications, 2008, 9 （5）: 842-846.

[3]. YUN Duan, SONG Qiang, YAO Qiang. Mechanism and analysis of SCR catalyst deactivation [J].Coal Conversion, 2009, 32 (1) : 91-96. 
[4]. ZHENG Y J, JEBSEN A D, JOHNSSON J E. Deactivation of $\mathrm{V}_{2} \mathrm{O}_{5}-\mathrm{WO}_{3}-\mathrm{TiO}_{2}$ SCR catalyst at a biomass-fired combined heat and power plant[J].Applied Catalysis B: Environmental, 2005, 60 (3/4):253-264.

[5]. TANG F S, XU B L, SHI H H, et al. The poisoning effect of $\mathrm{Na}+$ and $\mathrm{Ca}_{2}+$ ions doped on the $\mathrm{V}_{2} \mathrm{O}_{5} / \mathrm{TiO}_{2}$ catalysts for selective catalytic reduction of $\mathrm{NO}$ by $\mathrm{NH}_{3}[\mathrm{~J}]$. Applied Catalysis B: Environmental, 2010,94 (1/2): 71-76.

[6]. ODENBARAND C U I. Thermal stability of vanadia SCR catalysts for the use in diesel applications[J]. Chemical Engineering Research and Design, 2008, 86 （7）: 663-672.

[7]. SHANG Xue-song, CHEN Jin-sheng, ZHAO Jin-ping, et al. Discussion on the deactivation of SCR denitrification catalyst and its reasons[J]. Journal of Fuel Chemistry and Technology, 2011, 39 (6) : 465-470.

[8]. CHEN Jin-sheng, SHANG Xue-song, ZHAO Jin-ping, et al. Performance determination and evaluation of denitration catalyst in flue gas[J]. Electric Power, 2010, 43 (11) : 64-69.

[9]. SHANG Xue-song, CHEN Jin-sheng, HU Gongren, et al. Comparison and analysis of the performance of flue gas denitrification catalyst with different operating time[J]. Electric Power, 2012, 45 (1) : 45-49.

[10]. Guideline for the Testing of DENOX Catalysts. VGB-R302 He, 1998. 